\title{
CAPÍTULO 05: CONTROLE HIGIÊNICO-SANITÁRIO NA COCÇÃO A VÁCUO DE REFEIÇÕES COLETIVAS
}

\section{CAPÍTULO 05: CONTROL HIGIÉNICO-SANITARIO EN LA COCCIÓN AL VACÍO DE COMIDAS COLECTIVAS}

\section{CHAPTER 05: HYGIENIC-SANITARY CONTROL IN VACUUM COOKING OF COLLECTIVE MEALS}

\author{
Janete Lana da Silva ${ }^{1}$; Sheyla Maria Barreto Amaral ${ }^{2}$; Marlene Nunes Damaceno ${ }^{3}$
}

DOI: $\underline{\text { https://doi.org/10.31692/978-65-88970-18-8.47-67 }}$

\section{RESUMO}

Esse estudo objetiva avaliar a qualidade higiênico-sanitária do beneficiamento de refeições coletivas submetidas ao processo de cocção à vácuo em conformidade com a legislação vigente. A pesquisa se caracteriza com a finalidade aplicada, de natureza observacional e experimental, com abordagem qualitativa, do tipo descritiva, exploratória e explicativa, com procedimentos em campo e desenvolvimento longitudinal, realizada no período de 120 dias, em empresa fornecedora de refeições. Inicialmente, foram ministradas palestras, durante os turnos de trabalho, conscientizando os manipuladores sobre as práticas corretas de higienização das mãos e das Boas Práticas de Fabricação. Em seguida, iniciou-se a implementação das etapas de controle higiênico-sanitário da produção (adequação dos agentes químicos de limpeza, monitoramento, sanitização dos equipamentos, elaboração dos Procedimentos Operacionais Padronizados (POP) e acompanhamento do beneficiamento de legumes e carnes). Os colaboradores responsáveis pela limpeza foram orientados sobre as diluições, a aplicação, o tempo de contato e a função de cada agente; a forma correta da limpeza e higienização dos equipamentos. Elaborou-se quatro POP para as unidades produtoras de alimentos (Higienização de instalações, equipamentos, móveis e utensílios; Controle da potabilidade da água; Higiene e saúde dos manipuladores; e Controle integrado de vetores e pragas urbanas). A frequência do controle, de cada etapa de beneficiamento, foi realizada diariamente e as condições higiênico-sanitárias do beneficiamento dos legumes e das carnes apresentaram conformidade com a legislação, manifestando a qualidade das refeições coletivas produzidas. $\mathrm{O}$ acompanhamento do beneficiamento das refeições coletivas submetidas ao processo de cocção à vácuo dos legumes e carnes indicou que é possível elaborar refeições atendendo os padrões de qualidade higiênica e sanitária exigidos pela legislação, fornecendo assim um alimento seguro para os consumidores.

Palavras-Chave: Boas Práticas de Fabricação, Higienização, Manipuladores, Tratamento térmico.

\section{RESUMEN}

Este estudio tiene como objetivo evaluar la calidad higiénico-sanitaria del procesamiento de comidas colectivas sometidas al proceso de cocción al vacío de acuerdo con la legislación vigente. La investigación se caracteriza por el propósito aplicado, de carácter observacional y experimental, con un abordaje cualitativo, de tipo descriptivo, exploratorio y explicativo, con procedimientos en campo y desarrollo longitudinal, realizado en el plazo de 120 días, en una empresa proveedora de comidas. Inicialmente, se impartieron conferencias, durante los turnos de trabajo, concienciando a los manipuladores sobre las prácticas correctas de higiene de manos y las Buenas Prácticas de Fabricación. Luego, la implementación de las etapas de control higiénico-sanitario de producción (adecuación de agentes químicos de limpieza, monitoreo, higienización de equipos, elaboración de Procedimientos Operativos Estandarizados (POE) y monitoreo del procesamiento de vegetales y carnes). Se instruyó a

\footnotetext{
${ }^{1}$ Tecnóloga em Alimentos, Instituto Federal de Educação, Ciência e Tecnologia do Ceará Campus Limoeiro do Norte, janetelana1@hotmail.com

${ }^{2}$ Mestranda em Tecnologia de Alimentos, Instituto Federal de Educação, Ciência e Tecnologia do Ceará Campus Limoeiro do Norte, sheylaamaral82@gmail.com

${ }^{3}$ Docente permanente, Instituto Federal de Educação, Ciência e Tecnologia do Ceará Campus Limoeiro do Norte, marlene@ifce.edu.br
} 
los empleados responsables de la limpieza sobre las diluciones, la aplicación, el tiempo de contacto y el rol de cada agente; la forma correcta de limpiar y desinfectar el equipo. Se prepararon cuatro POE para las unidades productoras de alimentos (Limpieza de instalaciones, equipos, mobiliario y utensilios; Control de la potabilidad del agua; Higiene y salud de los manipuladores; y Control integrado de vectores y plagas urbanas). La frecuencia del control, en cada paso de procesamiento, se realizó diariamente y las condiciones higiénico-sanitarias del procesamiento de verduras y carnes cumplieron con la legislación, mostrando la calidad de las comidas colectivas producidas. El seguimiento del procesamiento de comidas colectivas sometidas al proceso de cocción al vacío de verduras y carnes indicó que es posible preparar comidas cumpliendo con los estándares de calidad higiénica y sanitaria exigidos por la legislación, brindando así un alimento seguro para los consumidores.

Palabras Clave: Buenas Prácticas de Manufactura, Higienización, Manipuladores, Tratamiento Térmico.

\begin{abstract}
This study aims to evaluate the hygienic-sanitary quality of the processing of collective meals submitted to the vacuum cooking process in accordance with current legislation. The research is characterized with the applied purpose, of an observational and experimental nature, with a qualitative approach, of the descriptive, exploratory and explanatory type, with procedures in the field and longitudinal development, carried out in the period of 120 days, in a company that supplies meals. Initially, lectures were given, during work shifts, making handlers aware of correct hand hygiene practices and Good Manufacturing Practices. Then, the implementation of the stages of hygienic-sanitary control of production (adequacy of chemical cleaning agents, monitoring, sanitization of equipment, elaboration of Standardized Operating Procedures (SOP) and monitoring of the processing of vegetables and meat). The employees responsible for cleaning were instructed on dilutions, application, contact time and the role of each agent; the correct way of cleaning and sanitizing the equipment. Four SOP were prepared for the food producing units (Cleaning of facilities, equipment, furniture and utensils; Control of water potability; Hygiene and health of handlers; and Integrated vector and urban pest control). The frequency of the control, in each processing step, was carried out daily and the hygienic-sanitary conditions of the processing of vegetables and meat were in compliance with the legislation, showing the quality of the collective meals produced. The monitoring of the processing of collective meals submitted to the vacuum cooking process of vegetables and meat indicated that it is possible to prepare meals in compliance with the standards of hygienic and sanitary quality required by the legislation, thus providing a safe food for consumers.
\end{abstract}

Keywords: Good Manufacturing Practices, Sanitization, Handlers, Heat Treatment.

\title{
INTRODUÇÃO
}

O mercado de refeições coletivas cresceu significativamente nas últimas décadas em todo mundo, além de ter evoluído na mesma proporção. A maior demanda por serviços de alimentação fora do lar está relacionada as mudanças no estilo de vida da população, aumentando a necessidade de encontrar alternativas criativas e concretas que possibilitem a melhoria constante e sistemática de qualidade e produtividade destas organizações (BARROS et al., 2019).

Dentre os vários aspectos relativos à crescente demanda pelos serviços de refeição fora do lar, a qualidade sanitária dos produtos oferecidos configura questão fundamental, principalmente considerando a amplitude do público atendido. Segundo levantamentos, dentre as Unidades de Alimentação e Nutrição (UAN's), ou, mais atualmente denominado como Unidades Produtoras de Refeições (UPR's), os restaurantes por peso ou self-service por quilo 
têm se destacado na ocorrência de surtos de doenças transmitidas por alimentos (MAGALHÃES, 2021).

De acordo com a Associação Brasileira das Empresas de Refeições Coletivas (ABERC, 2019), a dimensão e a importância do setor na economia nacional podem ser medidas a partir dos indicadores do segmento, somente em 2018, 13 milhões de refeições foram fornecidas por dia, com movimento anual de 19,3 bilhões de reais, ofertando 210 mil empregos diretos, com consumo diário de 7,5 mil toneladas de alimentos e receita anual de 2,6 bilhões de reais, entre impostos e contribuições, para os governos. Para o ano de 2020, a estimativa foi de 14,7 milhões de refeições/dia.

O aumento da competitividade entre as empresas e a necessidade do atendimento das normas de higiene e segurança dos alimentos levaram alguns países da Europa e dos Estados Unidos à busca por novos processos tecnológicos de produção de refeições durante as décadas de 60 e 70. Uma das soluções encontradas foi a centralização da produção, caracterizada pela produção em uma unidade denominada cozinha central, seguida do transporte para as cozinhas satélites, onde as preparações são reaquecidas e finalizadas. Destaca-se a elevada vida útil dos alimentos, porém, o custo de implantação é muito alto (MAGALHÃES, 2021).

O sistema convencional ou descentralizado de produção de refeições existente na época e ainda predominante no Brasil, é aquele no qual os alimentos são preparados próximo ao horário de serem servidos, depois mantidos em equipamentos conservadores de temperatura e servidos no mesmo local que foram elaborados (SILVA et al., 2015). Logo, expressa-se o cuidado com a qualidade sanitária e nutricional das refeições, onde as Boas Práticas de Fabricação devem ser seguidas e acompanhadas diariamente dentro das UAN's, com intuito de atenuar os perigos provocados pela ingestão de alimentos contaminados, compromentendo a saúde dos consumidores e a imagem da empresa (VIEIRA et al., 2016).

Uma das formas de conservação de alimentos que está em evidência é a técnica sous vide, consiste no acondicionamento à vácuo em embalagens plásticas termorresistentes, com alta barreira à gases. $\mathrm{O}$ alimento embalado é colocado em tanques com água aquecida entre 60 e $100{ }^{\circ} \mathrm{C}$, e em seguida é resfriado entre 2 e $4{ }^{\circ} \mathrm{C}$, prolongando a vidá útil do produto e reduzindo o risco de recontaminação durante o armazenamento (MOREIRA, 2019).

Diante do contexto, esse estudo teve como objetivo avaliar a qualidade higiênicosanitária do beneficiamento de refeições coletivas submetidas ao processo de cocção à vácuo e verificar a conformidade com a legislação vigente. 


\section{Boas Práticas de Fabricação e Procedimentos Operacionais Padronizados}

Os serviços de alimentação são fiscalizados pela Legislação Sanitária Federal, que regulamenta medidas de caráter geral, aplicáveis as indústrias e serviços de alimentação. Compete aos Serviços de Vigilância Sanitária, Municipais e Estaduais, estabelecer normas complementares, abrangendo os aspectos mais específicos dependendo da região (SILVA JÚNIOR, 2020).

Para que o serviço ou indústria possam comprovar a garantia de qualidade sanitária dos seus produtos, foram criadas as Boas Práticas de Fabricação (BPF) e os Procedimentos Operacionais Padronizados (POP) que abrangem um conjunto de medidas adotadas para o cumprimento das normas pela RDC $n^{\circ}$ 275/2002, complementada pela RDC $n^{\circ}$ 216/2004, buscando o aperfeiçoamento das ações de controle sanitário na área de alimentos visando a proteção à saúde da população (BRASIL, 2002; BRASIL, 2004).

A adoção de Programas de BPFs se faz necessária para propiciar a redução dos riscos de contaminação química, física e biológica na produção de alimentos. A elaboração dos POP's visa padronizar os procedimentos de limpeza e higienização e posteriormente, a elaboração do Manual de Boas Práticas, buscando o maior controle higiênico-sanitário no processamento e cocção a vácuo (TEIXEIRA, 2017).

\section{Conservação de alimentos pelo uso do calor}

Segundo Silva Júnior (2020) a escolha da temperatura e do tempo a serem usados no tratamento de um alimento depende do efeito que o calor exercerá sobre o alimento e dos outros métodos de conservação que serão empregados conjuntamente.

Cada alimento é diferente, sendo as exigências para o processamento diferentes também. Se não chegar a destruir todos os microrganismos, deve o tratamento térmico destruir aqueles mais prejudiciais e retardar ou prevenir o crescimento dos sobreviventes (SILVA; BONI; SCHLINDWEIN, 2019). Os alimentos crus ou parcialmente cozidos podem ser embalados em sacos plásticos especiais fechados à vácuo. $\mathrm{O}$ cozimento é feito com o alimento embalado em calor úmido (pasteurizado). Logo após, é rapidamente resfriado em corrente de resfriamento, equipamento criogênico ou em gelo. Devendo ser armazenado a $3{ }^{\circ} \mathrm{C}$ por 21 dias e reaquecido imediatamente antes do consumo (FELLOWS, 2019). 
A pasteurização é um tratamento térmico que elimina a grande maioria dos microrganismos patogênicos existentes no alimento. A temperatura não passa dos $100{ }^{\circ} \mathrm{C}$, sob pressão atmosférica normal (lenta- $65^{\circ} \mathrm{C} / 30$ min.; rápida-75 ${ }^{\circ} \mathrm{C} / 15$ a $20 \mathrm{seg}$.), podendo esse aquecimento ser produzido por vapor, água quente, radiações ionizantes, calor seco, microondas etc. Por não eliminar completamente a flora microbiana, deve ser associada a outra técnica de conservação, como por exemplo a refrigeração, garantindo prolongamento da vida útil do produto (BARROS et al., 2020; FELLOWS, 2019).

\section{Processo de cocção à vácuo}

O processo de coção a vácuo objetiva conservar alimentos crus ou parcialmente cozidos em recipientes plásticos ou laminados fechados/lacrados sob vácuo. A função da embalagem é conferir proteção ao alimento acondicionado, criando uma barreira contra contaminação de grau biológico, por meio do ataque de microrganismos aeróbios e da ação enzimática. A embalagem permite que o calor se transfira da água ou vapor para o alimento (OLIVEIRA; SANTOS, 2015).

O produto embalado à vácuo não tem contato com o oxigênio, proporcionando uma maior segurança, visto que há redução da atividade respiratória e metabólica, redução do escurecimento enzimático e da produção e ação do etileno no caso de vegetais, redução da perda da qualidade durante o armazenamento, bem como, diminuição do ataque de microrganismos que necessitam do oxigênio (FELLOWS, 2019; MOREIRA, 2019).

Em comparação com outros métodos de conservação, o cozimento à vácuo é um dos mais baratos, considerando a utilização de equipamentos de baixo custo. Outra vantagem, é que não deixa resíduos no produto, além de aumentar sua vida de prateleira. Essa técnica, bem como todas as outras que estão evidência, possui maior eficácia quando associada a outra, como por exemplo, o resfriamento do produto após a cocção à vácuo, resultando em refeições mais seguras, saborosas e nutritivas (LEITE et al., 2020; VIANA, 2020).

\section{Componentes nutricionais dos alimentos}

Os nutrientes presentes nos alimentos capazes de fornecer energia para o homem e para os animais são os carboidratos, as proteínas e as gorduras. Entretanto, assim como os alimentos são fonte de nutrientes para nosso desenvolvimento, eles também têm essa função para os microrganismos (FELLOWS, 2019). 
Os carboidratos (mono ou polissacarídeos) desempenham papel importante como fontes de energia, armazenadores de energia e unidades estruturais das células. Constituem a mais importante fonte energética, por causa do seu alto consumo. $\mathrm{O}$ amido, a sacarose e a lactose contribuem com 85\% do total de carboidratos dos alimentos (SANTOS, 2019).

As proteínas são moléculas de natureza heteropolimérica, de ocorrência universal na célula viva, constituindo cerca de 50\% de seu peso seco. Exercem várias funções entre as mais frequentes a de catalisadores biológicos (enzimas) e componentes estruturais das células (KROLING et al., 2018).

As gorduras, representadas por todos os triglicerídeos (óleos e gorduras), fazem parte juntamente com outros componentes especiais, dos chamados lipídeos. Certos tipos de lipídeos são utilizados pelo organismo como fontes de energia e outros são estruturais das células. Os triglicerídeos representam uma reserva imediata de energia como gorduras (tecido adiposo) em células animais e óleos nas sementes oleaginosas (SANTOS, 2019).

As vitaminas são substâncias orgânicas, não energéticas, que devem ser fornecidas ao corpo humano em quantidades pequenas. Muitas delas atuam como coenzimas de certas reações enzimáticas e outras exercem funções fisiológicas específicas. Elas são normalmente classificadas em hidrossolúveis e lipossolúveis (BRUHN, 2018).

Entre as solúveis em água temos a vitamina $\mathrm{C}$ (ácido ascórbico) e todas aquelas pertencentes ao complexo B (B1 ou tiamina, B2 ou riboflavina, B6 ou piridoxina, niacina, ácido fólico, biotina, B12 ou cobalamina, colina, etc.). Entre as solúveis nas gorduras temos as vitaminas A, D, E e K (SILVA; MIRANDA; MESQUITA, 2020).

Diante do considerável conteúdo nutricional presente nos alimentos, avaliar sua carga microbiana com o intuito de descobrir falhas e minimizá-las, pode proporcionar o aumento da sua vida de prateleira e reduzir o risco de serem recolhidos nos estabelecimentos comercializadores (TEIXEIRA, 2017). Consequentemente, esse controle tem implicação econômica, industrial e na saúde pública, por possibilitar o aumento da qualidade e produtividade e por promover a saúde humana, minimizando os riscos de toxiinfecções alimentares (JESUS et al., 2018).

\section{Doenças Transmitidas por Alimentos}

As doenças relacionadas ao consumo de alimentos são comuns em todos os países e tem se mostrado muito frequente não só em quantidade de surtos como na variedade de agentes etiológicos. Mesmo com todos os recursos técnicos disponíveis, como a implantação e 
implementação das Boas Práticas de Fabricação (BPF), Procedimentos Operacionais Padronizados (POP's) e o Sistema de Análise de Perigos e Pontos Críticos de Controle (APPCC) os surtos tem aumentado nos países onde a cultura do povo é deficitária, o investimento empresarial é mínimo e o poder de fiscalização das Vigilâncias Sanitárias é restrito (SILVA JÚNIOR, 2020).

Doenças Transmitidas por Alimentos (DTA's) são todas as ocorrências clinicas consequentes à ingestão de alimentos ou águas que estejam contaminados com microrganismos patogênicos (infecciosos, toxicogênicos, ou infestantes), substâncias químicas, objetos lesivos ou que contenham em sua constituição estruturas naturalmente tóxicas, ou seja, são doenças consequentes à ingestão de perigos biológicos, químicos ou físicos presentes nos alimentos (FERRARI; FONSECA, 2019).

Os surtos de DTA's, episódio em que duas ou mais pessoas apresentam doença semelhante após a ingestão de alimentos ou água, de mesma origem e onde a evidência epidemiológica ou análise laboratorial apontam os alimentos e/ou água como veículos da doença, decorrem geralmente de microrganismos como: Staphylococcus aureus, Salmonella spp, Yersinea enterecolitica, Camphylobacter jejuni, Escherichia coli, fungos, entre outros (ÁVILA et al., 2016).

Dentre as mais frequentes DTA's, quatro são citadas, a primeira, toxinose por enterotoxina estafilocócita, o microrganismo responsável encontra-se amplamente distribuído na pele, nariz e garganta do ser humano. Os sintomas mais comuns da intoxicação estafilocócica aparecem de uma a seis horas depois, média de quatro horas, após a ingestão e podem ser do tipo náusea, vômito, cólica abdominal, sudorese, dor de cabeça, e diminuição da temperatura corporal. Geralmente, tem duração de um a dois dias com índice de mortalidade baixa só acontecendo quando associada a outras doenças como, por exemplo, em crianças desnutridas e pessoas idosas (REGINATO et al., 2019).

Em segundo, o Botulismo, uma toxinose causada pela ingestão de alimentos que contêm a exotoxina produzida por Clostridium botulinum. Trata-se de uma neurotoxina que afeta a comunicação (sinapse) entre as células nervosas. A manifestação clínica principal é a paralisia simétrica descendente flácida aguda sem febre e sem alterações sensoriais, podendo progredir e comprometer o sistema respiratório (DALLASTRA et al., 2018).

A terceira é a salmonelose, trata-se de uma infecção alimentar na qual células viáveis de Salmonella spp são ingeridas ocasionalmente. E por último, a toxinfecção causada por Bacilus cereus que ocorre, em geral, quando os alimentos, após sua cocção, são mantidos sem refrigeração apropriada durante várias horas, antes de serem servidos. Muitas vezes, o 
aquecimento não é suficiente para destruir os esporos, frequente em cereais e hortaliças. O calor favorece a germinação dos esporos, a manutenção a uma temperatura propícia e a multiplicação das formas vegetativas, alcançando a dose infectante (SILVA, 2017).

\section{Limpeza e Sanitização na Indústria Alimentícia}

A limpeza e sanitização na indústria alimentícia são operações muito importantes no controle higiênico sanitário do alimento que deve ser exercido de modo que evite sua contaminação por microrganismos, insetos, roedores, e outros animais, bem como substâncias químicas, destacando que os riscos biológicos requerem maior atenção (FELLOWS, 2019).

Segundo Leonardi e Azevedo (2018), as principais fontes de contaminações dos alimentos são: Matéria prima (incluindo água); Ambiente (ar, equipamentos, embalagens, materiais diversos); e Pessoal (higiene pessoal e manuseio dos alimentos).

A limpeza e sanitização estão baseadas em uma sequência de quatro operações, segundo Silva Júnior (2020):

1. Pré-lavagem $\rightarrow$ limpeza inicial da sujidade macroscópica e grosseira utilizando-se água aquecida. Trata-se de uma operação de grande importância no sentido de reduzir a quantidade de resíduos aderentes aos equipamentos e, quando efetuada de forma adequada, chega a remover até $90 \%$ do material solúvel presente.

2. Limpeza com detergentes $\rightarrow$ é, talvez, a operação mais importante, exigindo um conhecimento aprimorado das características dos detergentes e das suas condições de emprego.

3. Enxágue $\rightarrow$ lavagem ou enxágue é realizada para eliminar os resíduos de detergentes, podendo ser usada água fria ou quente.

4. Sanitização $\rightarrow$ sanitização ou sanificação visa eliminar os microrganismos presentes nos equipamentos que não são removidos após os tratamentos realizados anteriormente. Poderá ser feita por meios físicos e mais comumente por meios químicos.

\section{A importância da Segurança alimentar}

Segurança Alimentar e Nutricional é a garantia do direito de todos ao acesso a alimentos de qualidade, em quantidade suficiente permanentemente, com base em práticas alimentares saudáveis e respeitando as características culturais de cada povo, manifestadas no ato de se alimentar. Esta condição não pode comprometer o acesso a outras necessidades essenciais, nem 
sequer o sistema alimentar futuro, devendo se realizar em bases sustentáveis. É responsabilidade dos estados nacionais assegurarem este direito e devem fazê-lo em obrigatória articulação com a sociedade civil, dentro das possibilidades (BRASIL, 2006).

O termo "Segurança Alimentar" começou a ser utilizado após o fim da Primeira Guerra Mundial. Com a traumática experiência da guerra, vivenciada, sobretudo na Europa, tornou-se claro que um país poderia dominar o outro controlando seu fornecimento de alimentos. A alimentação seria, assim, uma arma poderosa, principalmente se aplicada por uma potência em um país que não tivesse a capacidade de produzir por conta própria e suficientemente seus alimentos. Portanto, esta questão adquiria um significado de segurança nacional para cada país, apontando para a necessidade de formação de estoques "estratégicos" de alimentos e fortalecendo a idéia de que a soberania de um país dependia de sua capacidade de autosuprimento de alimentos (MALUF; MENEZES; MARQUES, 2019).

A segurança alimentar é de fundamental importância para a produção de alimentos ditos seguros, sendo essa uma preocupação das indústrias de alimentos. Os alimentos com carga microbiana elevada, acima dos padrões permitidos, têm sua vida de prateleira diminuída, além de aumentarem o risco de serem recolhidos às expensas dos fabricantes, por se constituírem uma ameaça de toxi-infecção ao homem (LEONARDI; AZEVEDO, 2018).

\section{METODOLOGIA}

\section{Caracterização do estudo}

O presente pesquisa se caracteriza com a finalidade aplicada, de natureza observacional e experimental, com abordagem qualitativa, do tipo descritiva, exploratória e explicativa, com procedimentos em campo e desenvolvimento longitudinal, realizada no período de 120 dias, em empresa fornecedora de refeições (GIL, 2008; SILVEIRA; CÓRDOVA, 2009; YIN, 2016).

Inicialmente foram realizados Diálogos Diários de Segurança (DDS) - palestras ministradas durante os turnos conscientizando os manipuladores sobre as práticas corretas de higienização das mãos e das Boas Práticas de Fabricação seguindo a RDC nº 216 (BRASIL, 2004), visando a integração da equipe colaboradora. Em seguida, iniciou-se a implementação das etapas planejadas para o controle higiênico-sanitário do processo produtivo realizado na empresa, descritas na Figura 01. 
Figura 01: Processo de supervisão do controle higiênico-sanitário do processo produtivo

Adequação dos agentes químicos de limpeza

Monitoramento da limpeza e sanitização dos equipamentos

Elaboração dos Procedimentos Operacionais Padronizados

Acompanhamento do processo de beneficiamento dos legumes

Acompanhamento do processo de beneficiamento das carnes

Fonte: Própria (2021)

\section{Processo geral de beneficiamento}

Os produtos tanto de origem animal quanto vegetal, eram embalados respeitando o fluxograma de produção (Figura 02). Para evitar a contaminação cruzada, na mudança de produto toda sala e equipamentos eram higienizados. Todos os produtos beneficiados na empresa possuíam prazo de validade de 37 dias a partir da data de fabricação.

Figura 02: Fluxograma geral de beneficiamento dos produtos

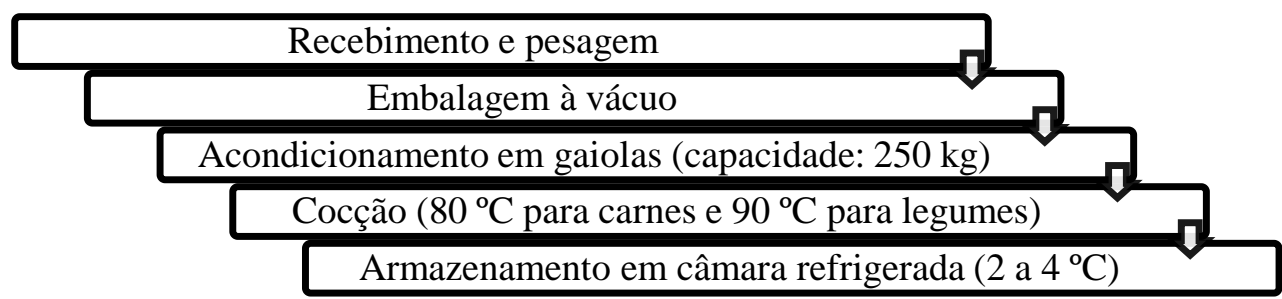

Fonte: Própria (2021).

\section{RESULTADOS E DISCUSSÃO}

\section{Orientação sobre a higienização correta das mãos}

Um dos fatores que requer atenção é a da higienização das mãos, pois, elas são veículos de transmissão de doenças através dos alimentos contaminados (FELLOWS, 2019). Os colaboradores foram orientados a higienizar sempre as mãos, de maneira correta, minimizando os riscos de contaminação de origem alimentar.

Cartazes de orientação foram afixados nas pias de higienização das mãos, fazendo com que o colaborador sempre lembrasse os passos a serem seguidos na higienização, explicando de forma simples e objetiva (Figura 03). 
Figura 03: Ilustrações com indicação sobre a forma correta de higienização das mãos.

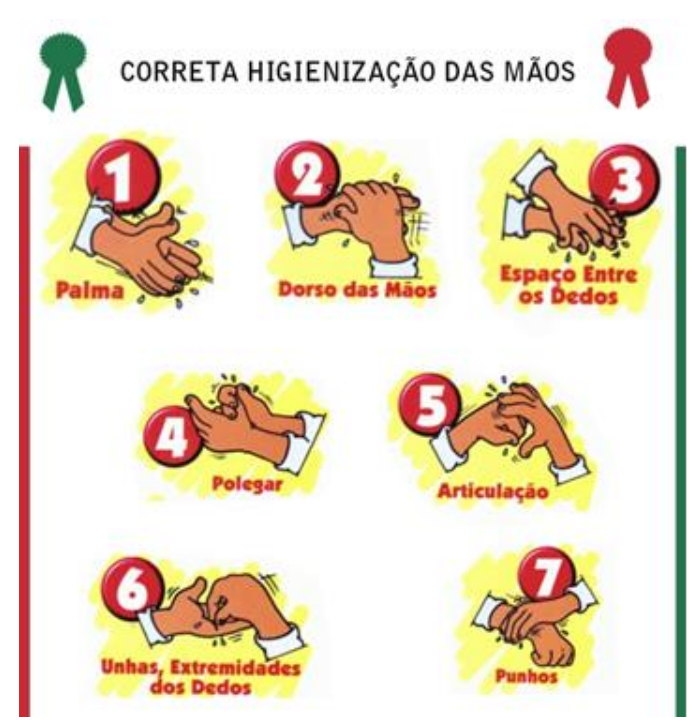

Fonte: https://sinproconhecer.sinprolondrina.com.br/tecnicas-de-lavagens-das-maos/

\section{Conscientização e treinamento das Boas Práticas}

Os colaboradores foram sempre orientados sobre a importância e aplicação das Boas Práticas na rotina diária. As Boas Práticas de Fabricação são uma ferramenta importante na produção de alimentos seguros, são regras ou procedimentos que devem ser utilizados na produção de alimentos destinados a prevenir os perigos (FELLOWS, 2019).

\section{Adequação dos agentes químicos de limpeza}

Os colaboradores responsáveis pela limpeza foram orientados sobre as diluições, o emprego e utilidade de cada agente, tempo de contato, e o porquê do uso. A adequação dos agentes químicos é importante, pois o uso inadequado faz com que a ação do agente químico seja ineficaz.

Segundo Silva Júnior (2020) os desinfetantes são empregados para o controle do desenvolvimento de microorganismo no ambiente, utensílios e equipamentos sendo os mais utilizados: cloro, iodo e quaternário de amônio. A água sanitária pode ter ação como alvejante e de desinfetante de uso geral, é uma solução aquosa à base de hipoclorito de sódio ou cálcio, com teor de cloro ativo entre 2,0 a 2,5\% p/p, durante o prazo de validade (máximo de 6 meses). Poderá conter apenas hidróxido de sódio ou cálcio, cloreto de sódio ou cálcio e carbonato de sódio ou cálcio como estabilizante (LEONARDI; AZEVEDO, 2018). 
Os colaboradores foram orientados sobre a forma correta da limpeza e higienização dos equipamentos. Esse monitoramento é feito visualmente e através de planilhas, buscando sempre corrigir as possíveis falhas do processo. No caso de falhas, os colaboradores são instruídos a refazer o processo.

Deve-se controlar a contaminação, multiplicação e sobrevivência microbiana, inaceitáveis no ambiente (equipamentos). A comprovação ou monitoração deve determinar se o nível de higiene é aceitável para, em um tempo hábil, efetuarem-se as correções necessárias, a fim de manter um controle do processo. Por esta razão, o método mais comumente utilizado para comprovar as condições de higiene dos equipamentos consiste em inspecioná-los após terem passado por um processo de limpeza (SILVA JÚNIOR, 2020).

\section{Elaboração dos Procedimentos Operacionais Padronizados}

Foram elaborados e implantados quatro POP's para as unidades produtoras de alimentos, de acordo com o estabelecido na RDC $n^{\circ} 275$ (BRASIL, 2002) e na RDC $n^{\circ} 216$ (BRASIL, 2004):

POP 1 - Higienização de instalações, equipamentos, móveis e utensílios: descrever a metodologia para higienização das instalações, equipamentos, móveis e utensílios utilizados nos processos relacionados com produção de alimentos a partir da cocção a vácuo.

POP 2 - Controle da potabilidade da água: descrever o método utilizado para assegurar a qualidade da água de forma a permitir a prevenção da contaminação dos alimentos e o consequente risco a saúde do consumidor.

POP 3 - Higiene e saúde dos manipuladores: estabelecer os requisitos a serem adotados para definir a conduta dos manipuladores no referente à higiene pessoal, hábitos e atitudes higiênicas assim como os controles necessários de saúde para prevenção de contaminação dos alimentos.

POP 4 - Controle integrado de vetores e pragas urbanas: descrever as atividades a serem realizadas para efetuar o controle integrado de vetores e pragas urbanas.

\section{Processo de beneficiamento dos legumes}

Os legumes utilizados na produção das refeições foram processados seguindo etapas adequadas para cada tipo, conforme descrição a seguir, e o controle higiênico-sanitário de cada 
etapa realizado diariamente.

i. Recebimento e pesagem $\rightarrow$ avaliação visual dos legumes, tamanho, peso, cor, aparência e estado físico. Os legumes fora do padrão, com injúrias mecânicas ou estragados eram rejeitados.

ii. Pré-limpeza $\rightarrow$ a lavagem em tanque com água onde são retiradas as sujidades, areia e folhas fora da área de manipulação, no corredor em caixas.

iii. Sanitização $\rightarrow$ legumes colocados na solução sanitizante (água + sanificante) por 15 minutos.

iv. Enxágue $\rightarrow$ feito o enxágue em água corrente.

v. Retirada das sementes $\rightarrow$ são retiradas as sementes (abóbora).

vi. Retirada das extremidades $\rightarrow$ são retiradas as extremidades (beterraba e cenoura).

vii. Descascamento $\rightarrow$ descascamento manual (batata-doce, chuchu e macaxeira) ou mecânico (beterraba e cenoura).

viii. Retirada total das cascas $\rightarrow$ é retirada o que restou de casca após o descascamento (batata inglesa e beterraba).

ix. Divisão $\rightarrow$ divide-se ao meio (abóbora, beterraba e chuchu).

x. Retirada do caroço $\rightarrow$ o caroço é retirado manualmente (chuchu).

xi. Corte $\rightarrow$ o corte é feito em cubos manualmente (abóbora e macaxeira) ou mecanicamente (batata inglesa, beterraba, cenoura e chuchu).

xii. Pesagem e Embalagem $\rightarrow$ adicionam-se $40 \mathrm{~g}$ de sal na pesagem e embala-se a vácuo.

xiii. Cocção (pasteurização) $\rightarrow$ em tanque por 40 minutos (abóbora), 1 hora (batata-doce, batata inglesa, cenoura, chuchu e macaxeira) ou 2 horas (beterraba) a $90{ }^{\circ} \mathrm{C}$.

xiv. Resfriamento $\rightarrow$ em tanque de resfriamento por 1 hora.

$\mathrm{xv}$. Etiquetagem $\rightarrow$ a embalagem é seca e posteriormente colocam-se as etiquetas.

xvi. Armazenamento $\rightarrow$ em câmara refrigerada com temperatura ente $2{ }^{\circ} \mathrm{C} \mathrm{e} 4{ }^{\circ} \mathrm{C}$.

\section{Processo de beneficiamento das carnes}

As carnes vermelhas eram recebidas e beneficiadas em ambiente refrigerado realizandose o processamento de cocção a vácuo em equipamento. Em alguns produtos era feito o chapeamento, funcionando como uma espécie de maquiagem, pois se fossem diretamente embalados após o beneficiamento no momento da cocção o aspecto do produto não se tornaria atrativo.

As proteínas presentes em maior quantidade nos produtos cárnicos têm suas 
particularidades e o beneficiamento notadamente requer algumas diferenças (FELLOWS,

2019). O controle higiênico-sanitário de cada etapa era realizado diariamente. A seguir descreve-se o beneficiamento por tipo de produto: carnes vermelhas, carnes brancas, vísceras e recheios.

Carnes vermelhas: Bife, cubo ou isca da paleta; bife do patinho; cupim e suíno assado; bife de carne do sol; bife de suíno.

i. Recebimento e pesagem $\rightarrow$ as carnes são recebidas e pesadas.

ii. Descongelamento $\rightarrow$ faz-se o descongelamento durante 24 horas sob refrigeração.

iii. Divisão $\rightarrow$ faz-se a divisão das peças maiores.

iv. Adição do tempero $\rightarrow$ adicionam-se os temperos (alho frito, óleo, colorau, caldo de carne, sal, alecrim e pimenta do reino).

v. Embalagem e selagem a vácuo $\rightarrow$ o produto embalado e selado a vácuo, os pacotes de cubo e de isca são de $5 \mathrm{~kg}$.

vi. Beneficiamento $\rightarrow$ é feito o beneficiamento da carne, a retirada da pele e corte dos bifes que pesam em media $75 \mathrm{~g}$ (carne de sol).

vii. Salga $\rightarrow$ é feita a salga dos bifes, por 24 horas (carne de sol).

viii. Desalga $\rightarrow$ a carne que já passou pelo processo de salga, passa por três lavagens a cada 30 minutos (carne de sol).

ix. Chapeamento $\rightarrow$ faz-se o chapeamento dos bifes (carne de sol e bife de suíno).

$\mathrm{x}$. Resfriamento $\rightarrow$ é feito em câmara de resfriamento rápido, para posterior embalagem. Deve ser resfriado rapidamente para que na embalagem não fique na zona de perigo (carne de sol e bife de suíno).

xi. Cocção (pasteurização) $\rightarrow$ é feita a cocção por 3 horas (bife de suíno), 3 horas e 30 minutos (bife de patinho e de carne do sol) ou 5 horas (bife, cubo ou isca da paleta) no tanque de cozimento a $80{ }^{\circ} \mathrm{C}$ ou por 6 horas a $90{ }^{\circ} \mathrm{C}$ (cupim e suíno assado).

xii. Resfriamento $\rightarrow$ feito em tanque de resfriamento por 1 hora.

xiii. Etiquetagem $\rightarrow$ a embalagem é seca e posteriormente colocam-se as etiquetas.

xiv. Armazenamento $\rightarrow$ é feito o armazenamento em câmara refrigerada com temperatura entre $2{ }^{\circ} \mathrm{C}$ e $4{ }^{\circ} \mathrm{C}$.

Carnes brancas: Bife e isca de frango; coxa de frango.

i. Recebimento e pesagem $\rightarrow$ os produtos são recebidos e pesados.

ii. Descongelamento $\rightarrow$ descongela-se durante 24 horas sob refrigeração. 
iii. Beneficiamento $\rightarrow$ faz-se o beneficiamento do filé de peito, retirando a gordura, e corte dos bifes e as iscas, os bifes têm dois padrões de peso de $75 \mathrm{~g}$ e $80 \mathrm{~g}$; retira-se parte da pele da coxa.

iv. Adição de temperos $\rightarrow$ adiciona-se os temperos (caldo de galinha, pimenta do reino, sal, óleo e colorau).

v. Chapeamento $\rightarrow$ faz-se o chapeamento dos bifes e das iscas, que funciona como uma maquiagem.

vi. Resfriamento $\rightarrow$ os bifes e as iscas são resfriados em câmara de resfriamento rápido, para posterior embalagem. Deve-se resfriar rapidamente para que na embalagem não fique na zona de perigo.

vii. Embalagem $\rightarrow$ os bifes são embalados em pacotes com 66 bifes $(75 \mathrm{~g})$ e em pacotes com 30 bifes ( $80 \mathrm{~g})$; as iscas são embaladas em pacotes de $5 \mathrm{~kg}$; as coxas em embalagens que contêm 7 coxas e em embalagens de $5 \mathrm{~kg}$.

viii. Cocção (pasteurização) $\rightarrow$ faz-se a cocção durante uma hora e quarenta minutos em tanque de cozimento a $80{ }^{\circ} \mathrm{C}$ (bifes e iscas) e por 3 horas a $80{ }^{\circ} \mathrm{C}$ (coxas).

ix. Resfriamento $\rightarrow$ feito em tanque de resfriamento por 1 hora.

$\mathrm{x}$. Etiquetagem $\rightarrow$ a embalagem é seca e posteriormente colocam-se as etiquetas.

xi. Armazenamento $\rightarrow$ é feito o armazenamento em câmara refrigerada com temperatura entre $2{ }^{\circ} \mathrm{Ce} 4{ }^{\circ} \mathrm{C}$.

Vísceras: Bife e isca de fígado; isca de bucho.

i. Recebimento e pesagem $\rightarrow$ faz-se o recebimento e pesagem.

ii. Descongelamento $\rightarrow$ é feito durante 24 horas sob refrigeração.

iii. Beneficiamento $\rightarrow$ retira-se a pele que fica na parte superficial do fígado e faz-se os bifes de peso médio de $80 \mathrm{~g}$; os buchos são cortados em isca.

iv. Chapeamento $\rightarrow$ faz-se o capeamento dos bifes.

v. Pré-cozimento $\rightarrow$ o bucho passa pelo processo de pré-cozimento por 3 horas, nessa etapa é adicionado vinagre, folha de louro, colorau.

vi. Resfriamento $\rightarrow$ é feito em câmara de resfriamento rápido, para posterior embalagem. Deve-se resfriar rapidamente para que na embalagem não fique na zona de perigo.

vii. Adição dos temperos $\rightarrow$ adiciona-se os temperos (alho frito e sal); nas iscas de bucho apenas alho frito.

viii. Embalagem $\rightarrow$ os bifes são acondicionados, 66 bifes em cada embalagem; as iscas em embalagens de $5 \mathrm{~kg}$. 
ix. Cocção (pasteurização) $\rightarrow$ faz-se a cocção por 1 hora em tanque de cozimento a $90{ }^{\circ} \mathrm{C}$ (bife e isca de fígado); e no bucho cozinha-se por 7 horas a $90^{\circ} \mathrm{C}$.

$\mathrm{x}$. Resfriamento $\rightarrow$ é feito em tanque de resfriamento por 1 hora.

$x i$. Etiquetagem $\rightarrow$ a embalagem é seca e posteriormente colocam-se as etiquetas.

xii. Armazenamento $\rightarrow$ é feito o armazenamento em câmara refrigerada com temperatura entre $2{ }^{\circ} \mathrm{Ce} 4{ }^{\circ} \mathrm{C}$.

Recheios: Carne do sol desfiada; frango desfiado e carne moída.

i. Recebimento e pesagem $\rightarrow$ são recebidas e pesadas.

ii. Beneficiamento $\rightarrow$ é feito o beneficiamento da carne, a retirada do tecido adiposo, até que a peça fique limpa, então se faz a divisão da carne em partes (carne do sol desfiada).

iii. Salga $\rightarrow$ é feita a salga em camadas, por 24 horas (carne do sol desfiada).

iv. Dessalga $\rightarrow$ a carne que já passou pelo processo de salga, passa por três lavagens a cada 30 minutos (carne do sol desfiada).

v. Descongelamento $\rightarrow$ é feito o descongelamento por 24 horas sob refrigeração (frango desfiado)

vi. Divisão $\rightarrow$ o peito de frango é divido em 4 cubos (frango desfiado).

vii. Cozimento $\rightarrow$ cozinha-se por 3 horas (carne do sol desfiada e frango desfiado); por 1 hora e quarenta minutos (carne moída).

viii. Desfiamento $\rightarrow$ é feito o desfiamento da carne no desfiador (carne do sol desfiada e frango desfiado).

ix. Adição dos temperos $\rightarrow$ adicionam-se os temperos (cebola roxa refogada e margarina carne do sol); (colorau, caldo de galinha, sal, pimenta do reino, cebola refogada, óleo, coentro, cebolinha, pimenta de cheiro - frango desfiado); (caldo de carne, colorau, pimenta do reino, cebola branca refogada, óleo, coentro, cebolinha - carne moída).

$\mathrm{x}$. Resfriamento $\rightarrow$ é feito em câmara de resfriamento rápido, para posterior embalagem. Deve-se resfriar rapidamente para que na embalagem não fique na zona de perigo.

xi. Embalagem $\rightarrow$ todos os produtos são embalados em porções de 2 e $5 \mathrm{~kg}$.

xii. Cocção (pasteurização) $\rightarrow$ é feita a cocção por 2 horas em tanque de cozimento a $90^{\circ} \mathrm{C}$ nos três produtos.

xiii. Resfriamento $\rightarrow$ é feito em tanque de resfriamento por 1 hora.

xiv. Etiquetagem $\rightarrow$ a embalagem é seca e posteriormente colocam-se as etiquetas.

Xv. Armazenamento $\rightarrow$ é feito o armazenamento em câmara refrigerada com temperatura entre $2{ }^{\circ} \mathrm{Ce} 4{ }^{\circ} \mathrm{C}$. 
Ebone, Cavalli e Lopes (2011) avaliaram as estratégias utilizadas para a gestão da qualidade higiênico-sanitária em unidades produtoras de refeições comerciais de Florianópolis, através de entrevistas com os gerentes, investigando a caracterização dos locais, porte, forma jurídica, capacidade ocupacional, número de refeições servidas e descrição dos sistemas e atividades da gestão da qualidade. Quase $80 \%$ das unidades utilizavam métodos operacionais no controle de qualidade, contudo, observou-se a necessidade de melhoria na estrutura física, aquisição de novos equipamentos e investimento na capacitação dos colaboradores.

Miranda e Barreto (2012) realizaram um diagnóstico das condições higiênico-sanitárias de unidades de comercialização de carne-de-sol no município de Cruz das Almas-BA, analisando o cumprimento da legislação vigente em 14 estabelecimentos envolvendo supermercados, minimercados, açougues e boxes que foram avaliados por meio de um estudo descritivo observacional, através de contato direto. Entre as unidades estudadas, apenas os supermercados seguiam os critérios estabelecidos na legislação, seguido dos minimercados. Esses resultados estão associados a falta de treinamento e de capacitação dos manipuladores.

Oliveira et al. (2017) avaliaram as boas práticas de fabricação durante a produção de alimentos, verificando a conformidade com a legislação, através de um estudo observacional do tipo transversal quali-quantitativo em 18 estabelecimentos. Todas as unidades avaliadas apresentavam insuficiência na qualidade higiênico-sanitária. Identificaram a necessidade de adequação em quase todas as etapas de elaboração e distribuição dos alimentos. Além da necessidade de melhorias no processo produtivo e na estrutura dos locais, o investimento em capacitação dos colaboradores foi destacado, diante dos resultados obtidos na pesquisa.

Susin et al. (2017) analisaram as condições higiênico-sanitárias, estruturais e de funcionamento de 148 UAN's do Rio Grande do Sul, objetivando identificar quais fatores estavam associados às condições insatisfatórias, por meio de um estudo observacional com delineamento transversal. Os resultados mostraram que as condições estruturais das unidades podem comprometer a segurança dos alimentos elaborados, visto que não são favoráveis a aplicação correta das BPF's. Diante disso, foi sugerido que a concessionária de alimentação coletiva responsável pelas UAN's elabore um plano de ação para as não conformidades encontradas, visando atenuar as irregularidades e sigam monitorando as etapas de produção e a execução do plano em cada unidade.

Pode se perceber que o presente trabalho difere dos estudos citados acima, visto que as condições higiênico-sanitárias do beneficiamento dos legumes e das carnes apresentavam conformidade com a legislação, manifestando a qualidade das refeições coletivas produzidas. 


\section{CONCLUSÕES}

O acompanhamento do processo de beneficiamento dos legumes e das carnes possibilitou verificar que é possível elaborar refeições atendendo os padrões de qualidade higiênica e sanitária exigidos pelas legislações, fornecendo assim um alimento seguro para os consumidores.

Cabe ainda lembrar que, mesmo estando em conformidade com as resoluções, as Unidades Produtoras de Refeições não podem descontinuar o monitoramento das etapas de produção, devem seguir as recomendações e investir na capacitação e qualificação de pessoal, realizando também treinamentos com os colaboradores.

Sugere-se para estudos futuros, a aplicação de uma lista de verificação (check list) contendo questões sobre edificação e instalações, manipuladores, equipamentos e utensílios, origem da matéria-prima, dentre outros, avaliando todo o estabelecimento, não apenas as condições do processo produtivo e qualidade final das refeições.

\section{REFERÊNCIAS}

ABERC. Associação Brasileira das Empresas de Refeições Coletivas. Mercado Real. 2019. Disponível em: https://www.aberc.com.br/mercadoreal.asp?IDMenu=21. Acesso em: 21 abr. 2021.

ÁVILA, M. de O.; SANTOS, P. H. da S.; GOIS, F. N. de; FURTADO, M. de C.; REIS, I. A. de O. A importância do controle das condições microbiológicas e higiênico sanitárias na prevenção de doenças transmitidas por alimentos - uma revisão de literatura. Revista Expressão Científica, v. 1, n. 1, p. 01-12, 2016.

BARROS, D. M; SILVA, A. P. F; MOURA, D. F; MEDERIOS, S. M. F. R. S; CAVALCANTI, I. D. L; SILVA, J. H. L; LEITE, A. R. F; SANTOS, J. M. S. Principais Técnicas de Conservação dos Alimentos. Brazilian Journal of Development, v. 6, n. 1, p. 806-821, 2020.

BARROS, N. V. dos A.; DE OLIVEIRA, A. P.; ARAÚJO, M. da C.; SOARES, I. F.; DA SILVA, N. C. Avaliação da qualidade higiênico-sanitária em restaurantes self-service do município de Picos-PI. Revista Interdisciplinar, v. 12, n. 2, p. 53-60, 2019.

BRASIL. Ministério da Saúde. Agência Nacional de Vigilância Sanitária. Resolução n 275 de 21 de outubro de 2002. Dispõe sobre o Regulamento Técnico de Procedimentos Operacionais Padronizados aplicados aos Estabelecimentos Produtores/Industrializadores de Alimentos e a Lista de Verificação das Boas Práticas de Fabricação em Estabelecimentos Produtores/Industrializadores de Alimentos. Diário Oficial da União, Brasília, DF, 06 nov. 2002, n. 206, Seção 1, p. 126-130. 
BRASIL. Ministério da Saúde. Agência Nacional de Vigilância Sanitária. Resolução no 216 de 15 de setembro de 2004. Dispõe sobre Regulamento Técnico de Boas Práticas para Serviços de Alimentação. Diário Oficial da União, Brasília, DF, 16 set. 2004, n. 179, Seção 1, p. 25-28.

BRASIL. Lei $\mathrm{n}^{\circ} .11 .346$ de 15 de setembro de 2006. Cria o Sistema Nacional de Segurança Alimentar e Nutricional (SISAN) com vistas em assegurar o direito humano à alimentação adequada e dá outras providências. Diário Oficial da União, Brasília, DF, 18 set. 2006, n. 179, Seção 1, p. 1-2.

BRUHN, F. H. P. Estudo da retenção de vitaminas lipossolúveis e hidrossolúveis empregando cromatografia com fluído supercrítico de ultra alta eficiência e desenvolvimento de métodos de acordo com os conceitos de analytical quality by desing. 2018. 154 p. Dissertação (Mestrado em Química). Instituto de Química, UNICAMP, 2018.

DALLASTRA, E. D. G.; BARBOSA, M. C.; SILVA, F. M. P. DA; SILVA, J. F. M. Botulismo, um problema de saúde pública. Revista Desafios, v. 5, n. 3, p. 142-150, 2018. https://doi.org/10.20873/uft.2359-3652.2018v5n3p142

EBONE, M. V.; CAVALLI, S. B.; LOPES, S. J. Segurança e qualidade higiênico-sanitária em unidades produtoras de refeições comerciais. Revista de Nutrição, v. 24, n. 5, p. 725-734, 2011.

FELLOWS, P. J. Tecnologia do processamento de alimentos: Princípios e práticas. 4 ed. Porto Alegre: Artmed, 2019.

FERRARI, A. M.; FONSECA, R. V. Conhecimento de consumidores a respeito de doenças transmitidas por alimentos. UNESC em Revista, v. 3, n. 1, p. 1-12, 2019.

GIL, A. C. Métodos e técnicas de pesquisa social. 6 ed. São Paulo: Atlas, 2008.

JESUS, E. P.; COSTA, C.; SOUSA, F. A.; SILVA, F. B. Importância da vigilância sanitária na administração pública - Revisão Sistemática. Revista GeTeC, v. 7, n. 17, p. 138-155, 2018.

KROLING, I.; CANUTO, S. H. R.; BRITO, K. S. DE; STIEVEN, A. C. Quantificação de proteínas provenientes em alimentos típicos do estado de Mato Grosso. ConnectionlineRevista Eletrônica do Univag, n. 18, 2018.

LEITE, J. F.; FEITOSA, A. C.; ZUNIGA, A. D. G.; GUIDA, L. M.; SILVA, D. X. da. Qualidade do fruto do pequi (Caryocar Brasiliense Camb.) armazenado sob vácuo em diferentes temperaturas. Brazilian Journal of Development, v. 6, n. 4, p. 21951-21958, 2020. https://doi.org/10.34117/bjdv6n4-385

LEONARDI, J. G.; AZEVEDO, B. M. Métodos de conservação de alimentos. Revista Saúde em Foco, v. 10, n. 1, p. 51-61, 2018.

MAGALHÃES, A. M. Empreendedorismo e aprendizagem em gestão de serviços de refeições fora do lar: a experiência da Lanchonete Escola NutriGD. Caminho Aberto: revista de extensão do IFSC, n. 14, p. 106-111, 2021. http://doi.org/10.35700/ca.2021.ano8n14.p106$\underline{111.3007}$ 
MALUF, R. S.; MENEZES, F.; MARQUES, S. B. Caderno 'Segurança Alimentar'. 2019. 52 p.

Disponível

em:

http://www.agencia.cnptia.embrapa.br/Repositorio/seguranca+alimentar_000gvxlxe0q02wx7 ha0g934vgwlj72d2.pdf. Acesso em: 21 abr. 2021.

MIRANDA, P. C.; BARRETO, N. S. E. Avaliação higiênico-sanitária de diferentes estabelecimentos de comercialização da carne-de-sol no município de Cruz das Almas-BA. Revista Caatinga, v. 25, n. 2, p. 166-172, 2012.

MOREIRA, C. J. Mandioca embalada a vácuo, pré-cozida e armazenada sob refrigeração. 2019. 33 p. Trabalho de Conclusão de Curso (Tecnologia em Alimentos). Departamento de Alimentos, UTFPR, 2019.

OLIVEIRA, C. C. de; BRASIL, C. C. B.; DA SILVA, J. P.; PEREIRA, L. S.; VERDUM, D. P.; ROIG, E. C. C.; BOHRER, C. T.; BOTTARO, S. M. Boas práticas de manipulação em estabelecimentos produtores de alimentos de uma cidade da região noroeste do Rio Grande do Sul. Segurança Alimentar e Nutricional, v. 24, n. 2, p. 141-152, 2017.

OLIVEIRA, E. N. A. de; SANTOS, D. da C. Tecnologia e processamento de frutos e hortaliças. Natal: Instituto Federal do Rio Grande do Norte, 2015.

REGINATO, A. M.; VALIATTI, T. B.; SOBRAL, F. D. O. S.; ROMÃO, N. F. Avaliação microbiológica de queijo tipo mussarela fatiado comercializado em supermercados do município de Ji-Paraná-Rondônia. Revista Brasileira de Higiene e Sanidade Animal, v. 13, n. 1, p. 89-97, 2019.

SANTOS, J. A. R. dos. Carbohidratos, gorduras e proteínas: importância nutricional e suporte ao exercício prolongado. Revista Perspectiva: Ciência e Saúde, v. 4, n. 1, p. 13-42, 2019.

SILVA, B. B.; BONI, B. R.; SCHLINDWEIN, A. D. Tempo de exposição e temperatura de distribuição da refeição quente dos funcionários de uma unidade de alimentação e nutrição hospitalar de Florianópolis-SC. Revista Uningá, v. 56, n. 3, p. 132-140, 2019.

SILVA, D. G. da. Salmonelose. Revista Acadêmica Ciência Animal, v. 15, n. Suppl 2, p. 109112, 2017. http://dx.doi.org/10.7213/academica.15.S02.2017.A11

SILVA JÚNIOR, E. A. da. Manual de Controle Higiênico-Sanitário em Serviços de Alimentação. 8 ed. São Paulo: Livraria Varela, 2020.

SILVA, L. C.; SANTOS, D. B.; SÃO JOSÉ, J. F. B.; SILVA, E. M. M. Boas práticas na manipulação de alimentos em unidades de alimentação e nutrição. Revista Demetra: Alimentação, Nutrição \& Saúde, v. 10, n. 4, p. 797-820, 2015.

SILVA, L. de A. R. da; MIRANDA, Y. C.; MESQUITA, V. M. de M. Vitaminas. Pesquisa \& Educação a Distância, n. 19, 2020.

SILVEIRA, D. T.; CÓRDOVA, F. P. A pesquisa científica. In: GERHARDT, T. E.; SILVEIRA, D. T. (Org.). Métodos de pesquisa. Porto Alegre: Editora da UFRGS, 2009. 120 p. cap. 2, p. 31-42. 
SINPROCONHECER. Técnicas de lavagens das mãos. Disponível em: https://sinproconhecer.sinprolondrina.com.br/tecnicas-de-lavagens-das-maos/. Acesso em: 21 abr. 2021.

SUSIN, V.; PEREIRA, F. B.; GREGOLETTO, M. L. de O.; CREMONESE, C. Condições higiênico-sanitárias, estruturais e de funcionamento de unidades de alimentação e nutrição. Vigilância Sanitária em Debate: Sociedade, Ciência \& Tecnologia, v. 5, n. 1, p. 60-68, 2017.

TEIXEIRA, E. F. Avaliação do plano estratégico de implementação de boas práticas de fabricação de alimentos em uma unidade produtora de refeições. 2019. 71 p. Dissertação (Mestrado em Educação para a Saúde). Escola Superior de Tecnologia da Saúde de Coimbra, IPC, 2019.

VIANA, B. da C. Qualidade bromatológica e microbiológica da carne de peito de frango liofilizado em diferentes ambientes de armazenamento. South American Journal of Basic Education, Technical and Technological, v. 7, n. 1, p. 558-569, 2020.

VIEIRA, D. C. V.; OLIVEIRA, D. C. de.; NUNES, M. A.; MARTINS, A. D. de O.; SILVA, C. A. de S.; MARTINS, E. M. F.; SILVA, M. H. L. Avaliação das boas práticas em uma unidade de alimentação e nutrição escolar de Minas Gerais. Higiene Alimentar, v. 30, n. 252/253, p. 47-52, 2016.

YIN, R. K. Pesquisa qualitativa do início ao fim. Porto Alegre: Penso Editora, 2016. 